\title{
Performance assessment of a pilot-size vacuum rotation membrane bioreactor treating urban wastewater
}

\author{
Raafat Alnaizy $\cdot$ Ahmad Aidan $\cdot$ Haonan Luo
}

Received: 17 March 2011/Accepted: 23 August 2011/Published online: 22 September 2011

(C) The Author(s) 2011. This article is published with open access at Springerlink.com

\begin{abstract}
This study investigated the suitability and performance of a pilot-scale membrane bioreactor (MBR). Huber vacuum rotation membrane (VRM 20/36) bioreactor was installed at the Sharjah sewage treatment plant (STP) in the United Arab Emirate for 12 months. The submerged membranes were flat sheets with a pore size of $0.038 \mu \mathrm{m}$. The VRM bioreactor provided a final effluent of very high quality. The average reduction on parameters such as COD was from 620 to $3 \mathrm{mg} / \mathrm{l}$, BOD from 239 to $3 \mathrm{mg} / \mathrm{l}$, Ammonia from 37 to $2 \mathrm{mg} / \mathrm{l}$, turbidity from $225 \mathrm{NTU}$ to less than 3NTU, and total suspended solids from $304 \mathrm{mg} / \mathrm{l}$ to virtually no suspended solids. The rotating mechanism of the membrane panels permitted the entire membrane surface to receive the same intensive degree of air scouring, which lead to a longer duration. The MBR process holds a promising future because of its smaller footprints in contrast to conventional systems, superior effluent quality, and high loading rate capacity.
\end{abstract}

Keywords Biological - Bioreactor - Membrane .

Wastewater

\section{List of symbols}

$\begin{array}{ll}\text { APHA } & \text { American public health association } \\ \text { BOD } & \text { Biochemical oxygen demand } \\ \text { COD } & \text { Chemical oxygen demand }\end{array}$

R. Alnaizy $(\bowtie) \cdot$ A. Aidan

Chemical Engineering Department,

American University of Sharjah, PO Box 26666, Sharjah, UAE

e-mail: ralnaizy@aus.edu

H. Luo

Huber Technology Middle East, PO Box 120137,

SAIF, Sharjah, UAE

$\begin{array}{ll}\text { DAF } & \text { Dissolved air flotation } \\ \text { MBR } & \text { Membrane bioreactor } \\ \text { MLSS } & \text { Mixed liquor suspended solids } \\ \text { MLVSS } & \text { Mixed liquor volatile suspended solids } \\ \text { OLR } & \text { Organic loading rate } \\ \text { SMDD } & \text { Sharjah municipality drainage department } \\ \text { SRT } & \text { Solids retention time } \\ \text { STP } & \text { Sewage treatment plant } \\ \text { TKN } & \text { Total Kjeldahl nitrogen } \\ \text { TMP } & \text { Trans-membrane pressure } \\ \text { TSS } & \text { Total suspended solids } \\ \text { VRM } & \text { Vacuum rotation membrane }\end{array}$

\section{Introduction}

New and innovative technology for more efficient and effective treatment of raw municipal wastewater is always in pursuit. One of the newest and emerging technologies is membrane microfiltration (MF) or ultra filtration (UF) systems of activated sludge. Membrane separation is one of the most favored processes for removing micro- and nanoparticles (colloids) from gas or liquid streams such as wastewater. Membranes are seen to be a viable replacement for the traditional sedimentation tanks. Membrane bioreactors control the mixed liquor suspended solids (MLSS) concentration, which reduces the required reactor size and promotes the development of specific nitrifying bacteria, thereby enhancing ammonia removal, and produces less sludge (Trussell 2006). However, MBRs cannot compensate for poor process engineering and proper attention is imperative to the design detail for them to perform, both technically and financially (Brown and Caldwell 2005). Over 500 MBR units have been commissioned and many 
more are in the process of installation and commissioning around the globe (Sarin and Brechtelsbauer 2007). Complete solids removal, a significant disinfection capability, high rate, high efficiency organic and nutrient removal are all characteristics of the MBR, regardless of the wastewater type to be treated or the commercial process used (Judd 2006). MBRs eliminate the need for precise control of the solids retention time (SRT) to MLSS ratio or food to microorganisms $(\mathrm{F} / \mathrm{M})$ ratio. Thus, MBR adds a greater distance between reclamation and the risk of microbial disease (Sarin and Brechtelsbauer 2007). Though membrane prices have decreased significantly during the past years, operating costs of MBRs are still quite high due to higher energy consumption. In addition, the production rate of MBRs is ultimately limited by membrane fouling that is highly dependent on treated wastewater compositions, biomass characteristics, membrane characteristics, and operation conditions (Yuki et al. 2007).

Previous studies have examined various factors affecting the membrane fouling in MBRs, including MLSS concentrations (Le-Clech et al. 2003; Kimura et al. 2005), F/M ratio (Yamato et al. 2006), sludge characteristics (Ghosh 2006; Itonaga and Watanabe 2004; Rosenberger et al. 2006), and the amount and composition of microbial products (Yamato et al. 2006; Rosenberger et al. 2006; Itonaga et al. 2004; $\mathrm{Ng}$ et al. 2006). Nonetheless, existing mechanisms of membrane biofouling is not comprehensible and strategies to control membrane biofouling are not currently available because of the various operating conditions, membranes, and wastewater used. Moreover, only several studies have focused on microbial aspects, such as microbial colonization, biofilm formation, and microbial community structures on the membrane surfaces in MBRs (Chen et al. 2004; Zhang et al. 2006). The severity of membrane fouling is determined by the activated sludge characteristics, operating conditions, and membrane characteristics. The operating conditions, i.e. SRT, HRT, and organic loading rate (OLR), determine the activated sludge characteristics that are related to membrane fouling and the operating condition. Air scouring, non-continuous suction, backwashing, and cleaning reduce the membrane fouling. The fouling layer deposited on the surface of the membrane can be removed by means of shear (Hong et al. 2002). This shear is provided by scouring the air that is introduced into the interspaces between the plates. The air is introduced as cross flow and can effectively remove the fouling layer. This air also provides oxygen that leads to better biodegradability and helps maintain the solids suspension in the tank. The membrane performance is improved at noncontinuous suction compared to continuous suction MBR (Hong et al. 2002). The pressure-relaxation period, during which no permeate is drawn from the membrane, i.e. TMP is reduced to zero, the foulants are allowed to diffuse into the MLSS due to concentration difference. The result is a decrease in the accumulation of foulants on membrane surfaces. However, non-continuous suction operation is not feasible in a large scale operation. By using frequent backwash and aeration, the efficiency of reducing internal fouling of the membrane increases. Furthermore, the optimization of backwash frequency and duration is necessary to account for energy and permeate consumptions (Aidan Ahmed et al. 2000).

In this study, we address several issues of the MBR technology. Specifically, the study investigates the treatment of Sharjah municipal wastewater by Huber submerged membrane technology (Huber VRM 20/36). The objective of the study is to identify and tackle issues that could arise in the decision making process for the deployment of MBRs. We will consider performance, reliability, and removal efficiencies for the most important pollutants. Fouling investigation and optimization of filtration by means of short- and long-term tests under steady conditions are presented.

\section{Materials and methods}

\section{Experimental methods}

The pilot-size VRM 20/36 bioreactor was made available and installed in the Sharjah Municipality Drainage Department STP for a period of 12 months in a working and active environment. The MBR system consists of individual rotating VRM plates installed around a stationary hollow shaft. The membranes are polyethersulfone flat sheets (NADIR P-150F) ultrafiltration membranes with nominal pore size of $0.038 \mu \mathrm{m}$ arranged in circular fashion. The total nominal membranes area of the VRM is $108 \mathrm{~m}^{2}$ are configured in 144 plates with $0.75-\mathrm{m}^{2}$ filter surface area per plate. There are six modules per element with four plates per module that contain permeate channels, spacers, and permeate discharge nozzles. The submerged membrane operates at trans-membrane pressure (TMP) of less than 300 mbar with a maximum membrane flux of $301 / \mathrm{m}^{2} \mathrm{~h}$. The process would operate at an optimal flux of $18 \mathrm{l} / \mathrm{m}^{2} \mathrm{~h}$ at TMP of $<150$. The unit has a maximum permeate flowrate of $6 \mathrm{~m}^{3} / \mathrm{h}$ and an optimal flux of $3 \mathrm{~m}^{3} / \mathrm{h}$. Scouring air at $38 \mathrm{~m}^{3} / \mathrm{h}$ is introduced into the interspaces between the plates via two centrally arranged tubes. Permeate is drawn from each plate via permeate tubes that collect it to a common pipe. These horizontal pipes meet at a center manifold where the permeate exits the system. The membrane plates rotate at a constant rotational speed of $1.8 \mathrm{rpm}$ using only a $0.75-\mathrm{kW}$ motor. The rotation allows the membrane plates to be air scoured alternatively by two centrally placed air tubes, thereby reducing the scouring air requirements, see Table 1 and Fig. 1 . 
Table 1 List of the most important technical and operating characteristics of the VRM 20/36

\begin{tabular}{lc}
\hline Parameter & Value \\
\hline Total membranes area $\left(\mathrm{m}^{2}\right)$ & 108 \\
Surface area per plate $\left(\mathrm{m}^{2}\right)$ & 0.75 \\
Pore size $(\mu \mathrm{m})$ & 0.038 \\
Number of plates & 144 \\
Number of modules & 36 \\
4 plates per module & \\
Number of elements & 6 \\
6 modules per element & 18 \\
Optimal membrane flux $\left(1 / \mathrm{m}^{2} \mathrm{~h}\right)$ & \\
TMP $<150$ mbar & 30 \\
Maximum membrane flux $\left(1 / \mathrm{m}^{2} \mathrm{~h}\right)$ & \\
TMP $<300 \mathrm{mbar}$ & 3 \\
Optimal permeate flowrate $\left(\mathrm{m}^{3} / \mathrm{h}\right)$ & \\
TMP $<150$ mbar & 6 \\
Maximum permeate flowrate $\left(\mathrm{m}^{3} / \mathrm{h}\right)$ & \\
TMP $<300 \mathrm{mbar}$ & 38 \\
Scouring air $\left(\mathrm{m}^{3} / \mathrm{h}\right)$ at flux of $30 \mathrm{l} / \mathrm{m}^{2} \mathrm{~h}$ & 0.75 \\
Power drive $(\mathrm{kW}$ h) & \\
\hline
\end{tabular}

As depicted in Fig. 1, the VRM unit is preceded by a dissolved air flotation (DAF) unit to remove free and emulsified oily wastes. The raw sewage coming from the Sharjah Municipality Drainage Department (SMDD) flow divider is first screened through a $3 \mathrm{~mm}$ screen to reduce solids loading, and stabilize and optimize the DAF unit performance. The screened wastewater is pumped into the flocculation pipes that have several fissures for coagulants and/or flocculent additions. However, no flocculent or any other chemicals are added during the runs. The flow passes through the sedimentation tank, then to the inflow tank. A portion of the effluent is combined with compressed air and returned to the sedimentation tank in the DAF unit. DAF unit is employed to perform sedimentation, aeration and for the removal the oils and greases. The accumulated sludge (including scum cleaned out by scraper, and the sediment sludge) is pumped into a manhole, which join the SMDD sludge treating line. The pretreated influent of the raw wastewater is screened up to $3 \mathrm{~mm}$ size and it is free of grit, oil, and grease. It is supplied at constant flow during experimentation but the wastewater flowrate to the bioreactor may vary between one and $3.5 \mathrm{~m}^{3} / \mathrm{h}$. The screened, raw influent is pumped from the inflow tank via a submersible pump into the aeration chamber. The mixture of activated sludge and inflow is transferred by the recirculation pump, into the VRM chamber, and the mixture will return to the aeration chamber by over flow. The permeate pump draws permeate through the ultrafiltration membranes in the bioreactor at a vacuum (160-230 mbar). Permeate is then directed to the permeate tank. The permeate pump operates for a specified time interval; $8 \mathrm{~min}$ permeate with 2 min rest cycle.

\section{Analytical methods}

Samples were taken from the reactor once per day at different locations to analyze the performance of the treatment. Sampling was conducted in chemically inert and clean containers in accordance with ISO 5667-16. The containers were completely filled and sealed. Testing was

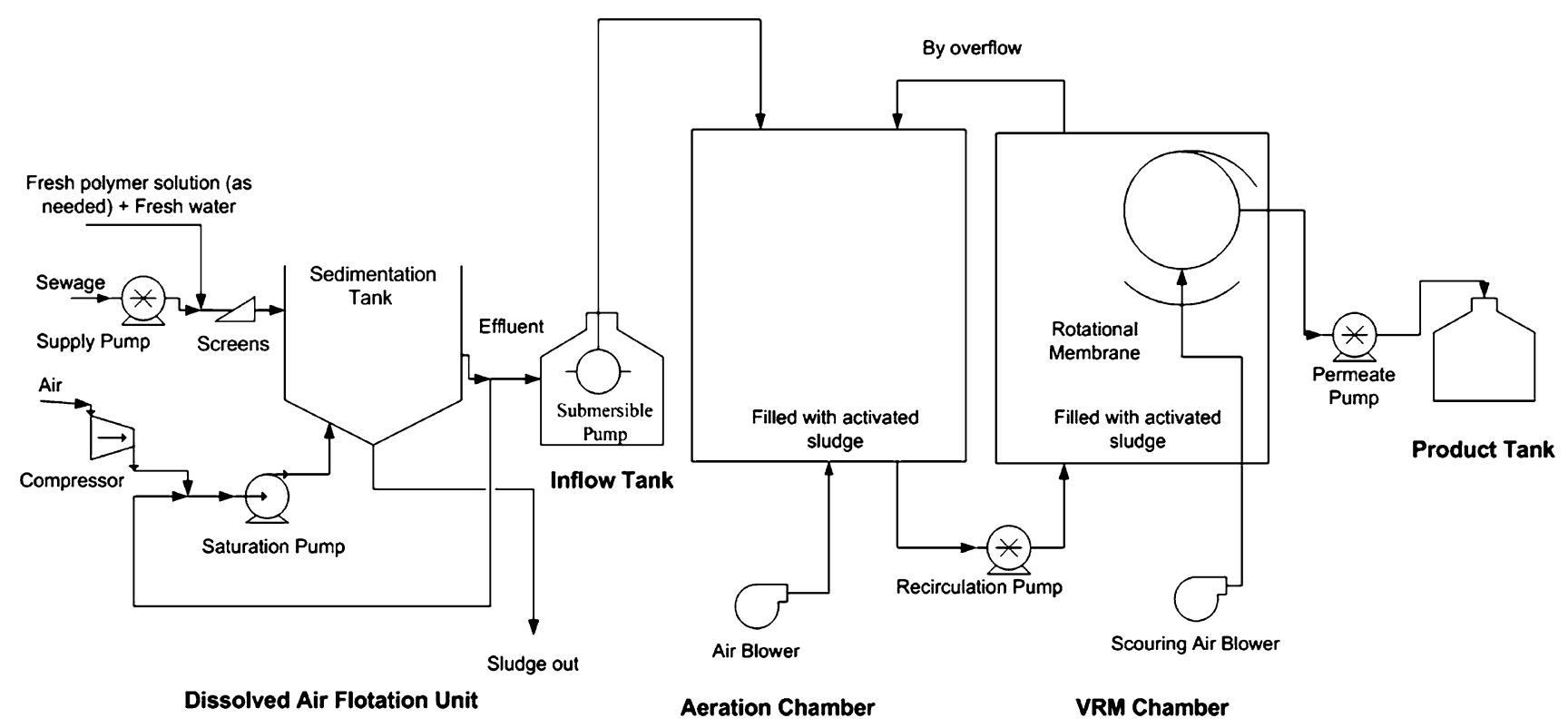

Fig. 1 Schematic representation of the pilot-size membrane-coupled activated sludge process to treat urban wastewater 
Table 2 The influent wastewater and permeate analyses methods

\begin{tabular}{ll}
\hline Parameter & Method \\
\hline COD & APHA 5220 D \\
BOD & APHA 5210 B \\
Conductivity & APHA 2510 B \\
TDS & APHA 2540 C \\
Suspended solids & APHA 2540 D \\
Ammonia as N & APHA 4500 $\mathrm{NH}_{3} \mathrm{E}$ \\
pH & APHA 4500 $\mathrm{H}^{+} \mathrm{B}$ \\
Total alkalinity as $\mathrm{CaCO}_{3}$ & APHA 2320 B \\
Nitrite as N & APHA 4500 NO \\
Total Kjeldahl nitrogen $(\mathrm{TKN})$ & APHA N $\mathrm{Org}_{2}$ \\
Phosphate as P & APHA 4500 P C \\
1/2-h Settleability & APHA 2710 C \\
Sludge volume index & APHA 2710 D \\
\hline
\end{tabular}

done immediately after collection or was stored at a temperature of $2-5^{\circ} \mathrm{C}$ in the dark for less than $12 \mathrm{~h}$. The influent wastewater and permeate was analyzed and characterized according to standard methods-American Public Health Association (APHA) 1998 or 2005. Table 2 shows the methods that were used to analyze for TSS, BOD, COD, phosphate, and others. The mixed liquor of suspended solids (MLSS) and mixed liquor volatile suspended solids (MLVSS) concentration was determined gravimetrically, in accordance with standard methods. Filtering was made on Grade GF/A glass fiber filters. Once the steadystate conditions were achieved in the reactor, short-term and long-term filtration tests were performed. Short-term filtration tests were conducted to evaluate critical flux. Long-term filtration tests were carried out by extracting a constant flux and controlling the TMP trend. It was performed to verify the maximum time after which the membrane fouling made a chemical cleaning indispensable.

\section{Results and discussion}

\section{Performance and reliability}

The performance of the pilot-scale membrane process with respect to removal efficiencies for the most important macro pollutants (COD, BOD, and others) and fouling was effectively evaluated. Investigation and optimization of filtration by means of short- and long-term trials under steady-state conditions were conducted successfully. Overall, the operations of the pilot-scale membrane process were trouble free and reliable within the investigation period of 1 year. Short-term interruptions of the continuous and automated system operation were mainly caused by external problems, such as "supply pump dry run", low level or completely dry inflow tank, and the aeration chamber level was very low. In addition, interruption of electrical current caused the control panels to shut off, which may have lead to the development of offensive odor due to the decomposition of the settled sludge. However, it did not affect the effluent conditions. The pretreated influent of the raw wastewater was high in suspended solid, but it was low in oil and grease contents. It did not cause any operational problems in the membrane units and no membrane defects occurred during the entire trial period. Wastewater flowrate fluctuation was handled with no problems within the performance limits of the membrane reactor at all times. The membrane flux adapted directly to the variation in influent flowrate $s$ without great delay because of the small hydraulic inertness of the submerged membrane systems. Based on these results, the basic operation of the tested pilot-scale MBR was viewed as safe, reliable, and fault-tolerant.

\section{Effluent quality and removal efficiency}

The average inflow concentration of COD was $620 \mathrm{mg} / \mathrm{l}$, BOD was $239 \mathrm{mg} / \mathrm{l}$, ammonia was $37 \mathrm{mg} / \mathrm{l}$, $\mathrm{pH}$ was 7.5 , total suspended solids (TSS) was $304 \mathrm{mg} / \mathrm{l}$, TKN was $46 \mathrm{mg} / \mathrm{l}$, phosphate was $10.2 \mathrm{mg} / \mathrm{l}$, and the turbidity was 225 NTU (Table 3). The VRM bioreactor provided a very high quality final effluent. Results indicated that the permeate from the VRM have, on average, $3 \mathrm{mg} / \mathrm{l}$ BOD, $3 \mathrm{mg} / \mathrm{l} \mathrm{COD}$, TKN $8 \mathrm{mg} / \mathrm{l}$, and $2 \mathrm{mg} / \mathrm{l}$ Ammonia. The turbidity was less than 3 NTU and virtually no suspended solids (Table 3).

The rejection of solid matters was complete during the entire trial period. Suspended solids were not detected in the permeate. The COD values determined in the permeate were on average, between 2 and $6 \mathrm{mg} / \mathrm{l}$. Occasionally, individual samples may exceed $27 \mathrm{mg} / \mathrm{l}$ or a minimum of nil. The COD concentrations of the influent varied very significantly between $300 \mathrm{mg} / \mathrm{l}$ and above $1,000 \mathrm{mg} / \mathrm{l}$ (Fig. 2). It was concluded that the COD removal efficiency in all samples at all times was in excess of $99 \%$. In the investigation, a clear relationship appeared between the influent and effluent parameters, which were partly illustrated in Fig. 2. Furthermore, it was concluded that the effluent requirements could be easily maintained. It was possible to achieve a COD of less than $30 \mathrm{mg} / \mathrm{l}$ in the effluent with the VRM bioreactor for the given influent wastewater characteristics.

The quantification of nitrogen was limited to the TKN and ammonia concentrations. The influent and effluent nitrogen concentrations (mean values from the daily samples) in the respective periods are summarized in Table 3 . The average TKN and ammonia nitrogen concentrations in the permeate were between nil and 9 and nil and $3 \mathrm{mg} / \mathrm{l}$, 
Table 3 Average influent (raw sewage) and effluent (permeate) quality and removal efficiency for the pilot-scale MBR plant and the existing conventional activated sludge process at SMDD

\begin{tabular}{|c|c|c|c|c|c|}
\hline & \multirow{2}{*}{$\begin{array}{l}\text { Influent raw } \\
\text { wastewater (mg/l) }\end{array}$} & \multicolumn{2}{|c|}{ Membrane-coupled activated sludge process } & \multicolumn{2}{|c|}{ Conventional (existing) activated sludge proces } \\
\hline & & Permeate $(\mathrm{mg} / \mathrm{l})$ & $\%$ Removal efficiency & Effluent (mg/l) & $\%$ Removal efficiency \\
\hline COD & 620 & 3 & 99.4 & 30.6 & 95.3 \\
\hline $\mathrm{PH}$ & 7.5 & 6.4 & - & 7.5 & - \\
\hline Ammonia & 31.5 & 2 & 95.8 & 12.2 & 61.3 \\
\hline BOD & 239 & 3.0 & 98.8 & 14.2 & 94.3 \\
\hline TSS & 304 & nd & 99.9 & 19.0 & 93.7 \\
\hline TDS & 1771 & 1568.4 & 11.5 & 1737.0 & 1.9 \\
\hline TKN & 46 & 8 & 81.5 & 29.7 & 37.5 \\
\hline Alkalinity & 272.8 & 22.1 & 91.9 & 172.0 & 37.0 \\
\hline Phosphate & 10.2 & 8.7 & 11.3 & 7.2 & 26.8 \\
\hline Turbidity & 225 & $<3$ & 98.3 & 32.0 & 84.0 \\
\hline
\end{tabular}

nd not detected

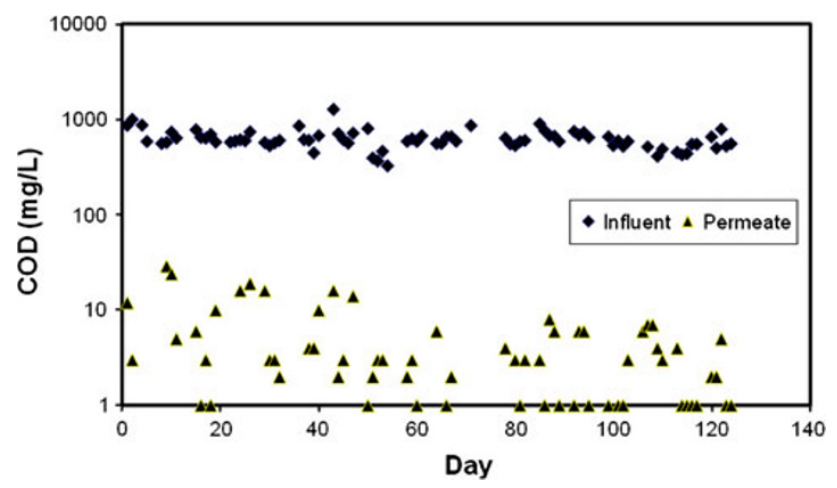

Fig. 2 COD values in the influent and effluent of the pilot-scale MBR (daily average sample)

respectively (Fig. 3). In addition, the achieved nitrogen removal, which included nitrogen incorporated in the excess sludge, and which was calculated from the daily loadings, is shown in Table 3. The mean nitrogen removal efficiency varied between $80 \%$ and more than $95 \%$. The higher nitrogen removal of the MBR compared to the conventional activated sludge process was due to a higher nitrification capacity of the MBR. The higher nitrification capacity was due to the higher concentration of MLSS in the activated sludge in MBRs. The higher MLSS and the increased oxygen transfer enhanced the ammonia and TKN oxidation, especially during moderate loading. In the existing conventional activated sludge process, the ammonia oxidation was impaired because of low sludge loading with consequently low oxygen consumption. Table 3 indicates the phosphate removal was higher in the conventional activated sludge system (26.8\%) compared to the MBR system (11.3\%)since the MBR systems were not dosed with chemicals to remove phosphate, whereas the conventional system in SMDD may have some chemical

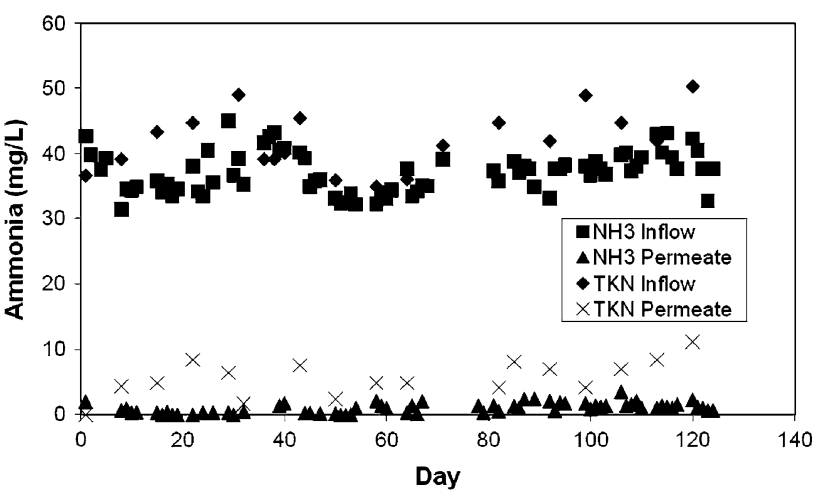

Fig. 3 TKN and ammonia concentrations in the influent and effluent of the pilot-scale MBR (daily average sample)

dosing. Additionally, the conventional systems have a larger settling stage, and phosphates are mainly removed by sedimentation.

\section{Hydraulic flexibility}

To assess hydraulic stability and hydraulic flexibility of the submerged membrane bioreactor, the flux-step method was conducted. The flux was incrementally increased for a fixed duration of time $(15 \mathrm{~min})$ for each increment. The influent flow was arbitrary varied between 25 and $100 \%$ of the variable frequency drive (VFD) that resulted in an actual flow between 0.832 and $3.16 \mathrm{~m}^{3} / \mathrm{h}$ and the corresponding fluxes were between 7.7 and $29.31 / \mathrm{m}^{2} \mathrm{~h}$ ). The required transmembrane pressure (TMP) for this operation was between 10 and 103 mbar. The results of the variable loading for the plant are represented in Fig. 4.

Figure 4 indicates that the TMP increased at the lowest flux of $7.7 \mathrm{l} / \mathrm{m}^{2} \mathrm{~h}$, from about 10 to $20 \mathrm{mbar}$ over the 15 min flux-step period. However, close observation of the 


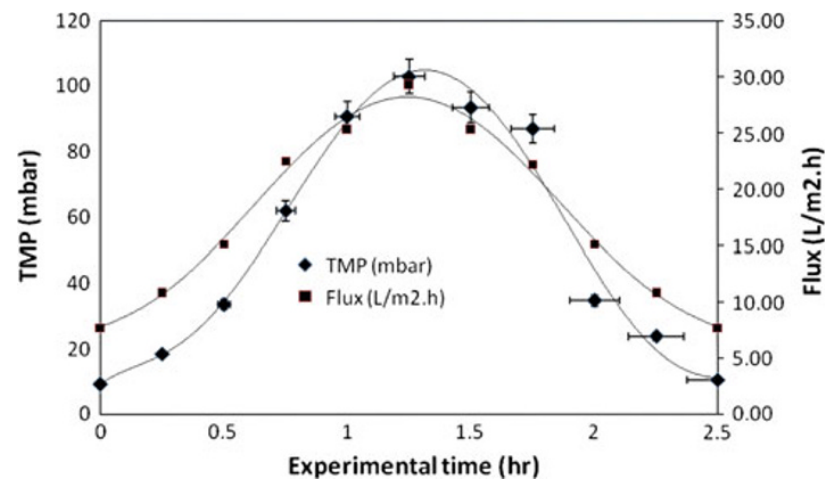

Fig. 4 Flux and transmembrane pressure for the pilot plant

TMP rate of increase at higher fluxes, above $151 / \mathrm{m}^{2} \mathrm{~h}$ shows a significant increase of TMP, from about 33 to 90 mbar, over the 15 min flux-step period. It can be concluded that the increase was due to the influence of the cake layer (fouling) at higher pressures or to fluxes. Also, the TMP values recorded during the descending phase are slightly greater than the corresponding values obtained during the ascending phase. For example, at the initial fluxstep of $7.7 \mathrm{l} / \mathrm{m}^{2} \mathrm{~h}$, TMP was 9.25 and $10.5 \mathrm{mbar}$ for the ascending and descending phases, respectively (Fig. 4). TMP profiles for ascending and descending phases were not symmetric because of the formation of a superficial (multilayer) initial irreversible fouling layer after the first flux-step cycle, on which some reversible fouling forms. This form of fouling corresponds to gel or deposit layer which can be considered as irreversible when the separation force is relaxed. This indicates that the membrane was not recovered fully from fouling during the descending phase. The TMP values related to irreversible fouling will be discussed further in "Permissible operating fluxes" below.

\section{Hydraulic permeability}

The effective hydraulic permeability in membrane filtration can be defined as the volumetric permeate flux divided by the transmembrane pressure. This parameter represents the productivity of the membrane per unit applied transmembrane pressure and is a simplified way of expressing the ultrafiltration rate since both permeate flux and transmembrane pressure change in response to variation in operating conditions (Ghosh 2006). As with all membranes, the hydraulic permeability of a membrane varies with thickness, pore size distribution, and pore density. Figure 5 shows results obtained from the submerged membrane experiment performed to observe the flux and hydraulic permeability for the pilot plant. The permeate flux increased but the transmembrane pressure also increased. Figure 5 signifies stable permeability has a close

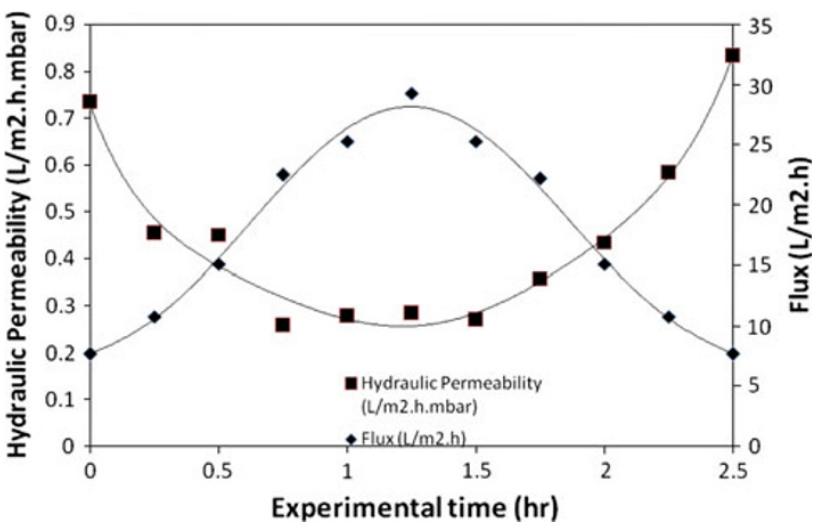

Fig. 5 Flux and hydraulic permeability for the pilot plant

relationship with the magnitude of the applied flux. It was possible to operate with a net flux of $301 / \mathrm{m}^{2} \mathrm{~h}$ to achieve a stable permeability of around $300 \mathrm{l} / \mathrm{m}^{2} \mathrm{~h}$ bar. Membrane fouling and concentration polarization are major limiting factors in membrane filtration processes permeability (Ghosh 2006). However, it was also feasible to recover the membrane performance after fouling without an intensive cleaning and to maintain stable permeability during peak flows.

Permissible operating fluxes

The critical flux is difficult to define because the limiting foulant in mixed liquor of the MBR needs to be defined. The effect of fouling can be observed in terms of the marginally lower permeate flux and the marginally higher transmembrane pressure. A plot of TMP versus constant flux is depicted in Fig. 6. Due to deposition, TMP rose slowly, and the rate of rise is less with more imposed shear or lower solids. In an idealized situation, TMP would remain unchanged at subcritical flux conditions, i.e. $25 \mathrm{~L} / \mathrm{m}^{2} \mathrm{~h}$ )

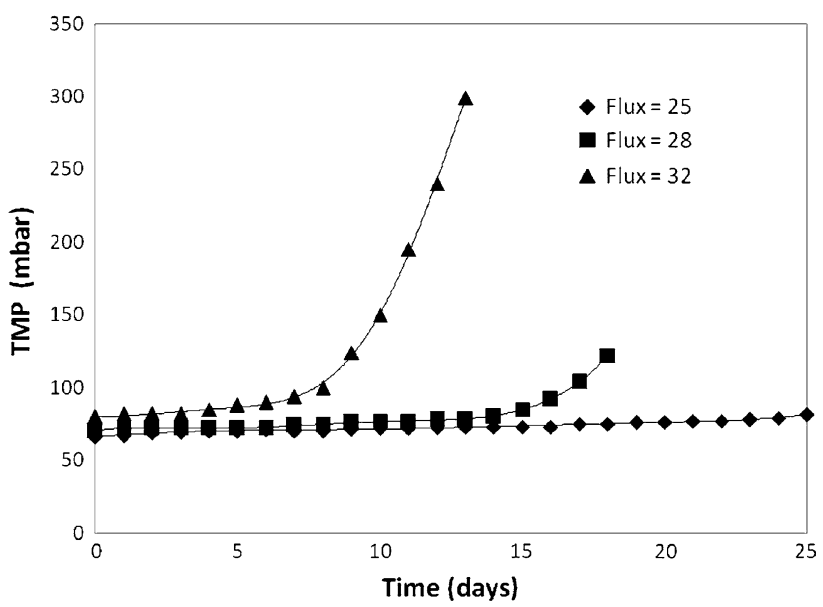

Fig. 6 Transmembrane pressure histories for constant flux operation applied to the pilot MBR 
(Fig. 6). Nonetheless, because of fouling due to feed characteristics, membrane properties, and hydrodynamic environment, some degree of TMP rise tends to occur at all fluxes. It is more practical to consider the sustainable flux, for which a differential change in transmembrane pressure with respect to time is relatively low. Figure 6 shows TMP variation (related to total and irreversible fouling at high flux and low flux) with membrane flux. It can be seen that the TMP values related to fouling increases exponentially at the higher flux, while the TMP values related to fouling increases linearly with a small gradient at the lower flux. Further, the differential change in TMP with respect to time is very small for fluxes less than $30 \mathrm{l} / \mathrm{m}^{2} \mathrm{~h}$ and therefore, it can be said that the critical irreversible fouling occurs when the flux is larger than $30 \mathrm{l} / \mathrm{m}^{2} \mathrm{~h}$.

\section{Foam formation}

During the experimental operation, excessive foam on the surface of the aeration tank was observed. Nevertheless, the treatment process and the permeate quality were not affected. It was only encountered at MLSS of over $40 \mathrm{~g} / \mathrm{l}$. The foam removal was done manually by means of water flushing. A secondary option was to drain a portion of activated sludge to reduce sludge concentration. On a regular basis, sludge was drained from the aeration chamber to reduce thick foaming inside the chamber caused by the high density of sludge. The foaming was due to shortcomings of the pilot plant as well. It is not expected to occur with the same magnitude in a commercial-size MBR because the sludge- recycle ratio would be more accurate and well planned during design, with careful consideration of SRT, temperature, and the influent quality. This does not guarantee that the foam issue will be completely eliminated but MLSS value of $40 \mathrm{~g} / \mathrm{l}$ during operation is not a standard operation parameter. It will vary from application to application. The MLSS should be limited to a certain level, depending on the foaming situation. At MLSS less than $20 \mathrm{~g} / \mathrm{l}$, the foam formation stopped completely. The temperature of the reactor was closely monitored from December to July. The reactor's temperature varied between 21 and $32^{\circ} \mathrm{C}$, which was lower than the high ambient temperature of Sharjah. The temperature interval was ideal for bacteria activity, and obviously the temperature was not controlled. In general, the bacteria are under water surface with no direct sun light; hence, no effect of temperature on the sludge. It only affected the excess foam, which formed due to dead bacteria.

\section{Practical aspects}

The VRM bioreactor employs rotating submerged membranes. The submerged membranes allow greater hydraulic efficiencies, reflected in greater permeability, due to their operation at substantially lower fluxes than side stream systems, since fouling tends to increase with increasing flux (Judd 2006). For such membranes, fouling is either internal (i.e. pore plugging or restriction) or surface (i.e. cake formation). Fouling mechanisms of a MBR process are very complex, as previously mentioned in the introduction section. The techniques used to control the fouling in the VRM are discussed below.

\section{Air scouring}

Foulants deposited on the surface of the membrane could be removed by means of air scouring. The scouring air was introduced as cross flow at $38 \mathrm{~m}^{3} / \mathrm{h}$ into the interspaces between the plates. Onsite experience with hollow fiber membrane systems demonstrated that fixed orientation resulted in more air scouring in the lower portion of the membranes and less at the surface. The rotating mechanism of the membrane panels in the VRM permitted the entire membrane surface to receive the same intensive degree of air scouring leading to longer durations between the necessities for chemical cleaning.

\section{Non-continuous suction}

In the VRM bioreactor, the permeate pump operated for a specified time interval; 8 min permeates and $2 \mathrm{~min}$ the rest cycle. During the rest cycle the TMP was zero and permeate was not drawn from the membranes. The foulants that were not attached irreversibly diffused away from the membranes into MLSS. Also, the air scouring during the rest cycle was more efficient because the TMP was zero and as a result the fouling layer on the surface of membranes was reduced.

\section{Cleaning}

The maximum TMP value that indicated a need for chemical cleaning was dependent on the start-up pressure, because depending on location of pumps, etc., the start-up pressure could be different from application to application. Hence, a decision must be asserted on the TMP. In our operation, if the pressure increases to approximately 300 mbar, a chemical cleaning cycle was performed. The rotating VRM plates of the MBR system were cleaned chemically after 101 days of operation. The cleaning process occurred in situ without removal of the plate module. The activated sludge was drained outside the VRM chamber. The filter driving motor operated continuously to apply water on the membrane, ensuring the membrane remained wet. Next, the chamber was filled with approximately 500 ppm of sodium hypochlorite solution until the 
membrane was completely immersed in the solution. The operation continued for several hours with the filter driving motor and scoring air blower operating, to allow sufficient reaction time for the chemicals to dissipate the thick sludge. The solution was drained and the chamber was filled with clean water. Thereafter, that water was drained. The cleaning and draining steps may be repeated according to actual applications. Finally, the chamber was filled with activated sludge and the system was returned to regular operation. The plate modules were not cleaned mechanically from the outside. For a large capacity VRM unit, another option would be to perform the cleaning process outside the activated sludge tank using the same cleaning steps, reinstall in the activated sludge tank, and return to normal operation.

\section{Conclusions}

The study demonstrated that the performance of the pilot plant in municipal wastewater treatment was assured and reliable. A stable hydraulic performance and permeability was guaranteed. A chemical cleaning of the membrane was performed at intervals of approximately 3 months. Variable influent volume flows did not affect the membrane's performance in processing municipal wastewater. COD removal was greater than $95 \%$ with a maximum effluent COD value of $27 \mathrm{mg} / \mathrm{l}$. Similarly BOD removal was more than $98 \%$ with an average effluent BOD of $2 \mathrm{mg} / \mathrm{l}$. The effluent turbidity was less than $0.1 \mathrm{NTU}$ and the TSS was very low. The TKN removal was more than $95 \%$ and the total nitrogen removal efficiencies were greater than $80 \%$. Total phosphorus removal ranged from 50 to $90 \%$. Assimilation was the main mechanism for TP removal. The membrane bioreactor has shown to meet requirements at all times and has demonstrated a high reliability. Stress loading tests have shown only minimal effects on the effluent water quality. The MBR process holds a promising future for a multitude of reasons, namely smaller footprints, less sludge, an effluent suitable for reuse in irrigation, and a high loading rate capacity. However, more work is needed to minimize fouling and to reduce operational (energy) costs. It is anticipated that more sewage treatment plants will employ membrane bioreactors processes in the near future.

Acknowledgments This work was a collaboration effort by the American University of Sharjah, Sharjah Academy of Scientific Research, Sharjah Municipality, UAE, and Huber Technology Middle East.

Open Access This article is distributed under the terms of the Creative Commons Attribution License which permits any use, distribution and reproduction in any medium, provided the original author(s) and source are credited.

\section{References}

Aidan A, Abdel-Jabbar N, Ibrahim TH, Nenov V, Mjalli F (2008) Neural network modeling and optimization of scheduling backwash for membrane bioreactor (MBR). Clean Technol Environ Policy J 10(4)

Chen C-L, Liu W-T, Chong M-L, Wong M-T, Ong SL, Seah H, Ng WJ (2004) Community structure of microbial biofilms associated with membrane-based water purification processes as revealed using a polyphasic approach. Appl Microbiol Biotechnol 63: $466-473$

Ghosh R (2006) Enhancement of membrane permeability by gas sparging in submerged hollow fiber ultrafiltration of macromolecular solutions: role of module design. J Membr Sci 274(1-2): $73-82$

Hong SP, Bae TH, Tak TM, Hong S, Randallb A (2002) Fouling control in activated sludge submerged hollow fiber membrane bioreactors. Desalination 143(2002):219-228

Itonaga T, Watanabe Y (2004) Performance of membrane bioreactor combined with pre-coagulation/sedimentation. Water Supply $4: 143-149$

Itonaga T, Kimura K, Watanabe Y (2004) Influence of suspension viscosity and colloidal particles on permeability of membrane used in membrane bioreactor (MBR). Water Sci Technol 50:301-309

Judd SJ (2006) Membrane bioreactor process fundamentals. In: Proceedings, Microfiltration IV conference, the National Water Research Institute (NWRI)

Kimura K, Yamato N, Yamamura H, Watanabe Y (2005) Membrane fouling in pilot-scale membrane bioreactors (MBRs) treating municipal wastewater. Environ Sci Technol 39:6293-6299

Le-Clech P, Jefferson B, Judd SJ (2003) Impact of aeration, solids concentration and membrane characteristics on the hydraulic performance of a membrane bioreactor. J Membr Sci 218: 117-129

Ng HY, Tan TW, Ong SL (2006) Membrane fouling of submerged membrane bioreactors: impact of mean cell residence time and the contributing factors. Environ Sci Technol 40:2706-2713

Rosenberger S, Laabs C, Lesjean B, Gnirss R, Amy G, Jekel M, Schrotter J-C (2006) Impact of colloidal and soluble organic material on membrane performance in membrane bioreactors for municipal wastewater treatment. Water Res 40:710-720

Sarin V, Brechtelsbauer P (2007) Wastewater treatment using MBR. Water Dig 2(1)

Trussell RR (2006) Membrane bioreactors and the future of wastewater treatment. In: Proceedings, Microfiltration IV conference, the National Water Research Institute (NWRI)

Wahlberg E, Melcer H, Bratby J, Molseed A (2005) The MBR revolution. Brown and Caldwell Quarterly Fall 33(3)

Yamato N, Kimura K, Miyoshi T, Watanabe Y (2006) Difference in membrane fouling in membrane bioreactors (MBRs) caused by membrane polymer materials. J Membr Sci 280:911-919

Yuki M, Yoshimasa W, Satoshi O (2007) Membrane biofouling in pilot-scale membrane bioreactors (MBRs) treating municipal wastewater: impact of biofilm formation. Environ Sci Technol 41(2):632-638

Zhang K, Choi H, Dionysiou DD, Sorial GA, Oerther DB (2006) Identifying pioneer bacterial species responsible for biofouling membrane bioreactors. Environ Microbiol 8:433-440 